\title{
Cultural Exchanges between China and Portuguese-speaking Countries: Macao Platform
}

\author{
Yu Huichun ${ }^{1, a,{ }^{*}}$
}

${ }^{1} \mathrm{PhD}$ Candidate, ISCR, Macau University of Science and Technology, Taipa, Macau, China

\author{
ahcyu@must.edu.mo
}

${ }^{*}$ Corresponding author

Keywords: China-Portuguese-speaking countries, Cultural exchange, Macao platform.

\begin{abstract}
The cooperation between China and Portuguese-speaking countries has expanded to 17 different areas and cultural cooperation is one of them. History has given Macao a profound cultural heritage which has enabled Macao to maintain close ties with Portuguese-speaking countries. Macao has natural advantages in terms of language, culture, geographical location, and policy. In this sense, Macao has the qualifications to become a platform for cultural exchanges between China and Portuguese-speaking countries. However, Macao also has its own shortcomings, such as small audiences and lack of cultural exchange mechanism. If Macao can combine the construction of platform with its local cultural and creative industries while giving full play to the government's leading role and encouraging non-governmental participation, Macao will certainly serve better as a bridge for cultural exchanges between China and Portuguese-speaking countries.
\end{abstract}

\section{中国与葡语国家文化交流中的澳门平台作用}

\author{
于会春 $1, a,{ }^{*}$
}

1澳门科技大学社会和文化研究所博士研究生, 函仔, 澳门, 中国

ahcyu@must.edu.mo

*通讯作者

关键词: 中国与葡语国家; 文化交流; 澳门中心

中文摘要. 中国与葡语系国家的合作领域已拓展至17个, 文化合作是其中之一。历史赋予澳 门的深厚文化底蕴使澳门长久以来保持着和葡语国家的紧密联系。澳门在语言、文化、地理 位置、制度和政策等方面存在天然优势, 具备成为中国与葡语国家文化交流中心的条件。但 澳门同样有其自身不足, 如受众小、文化交流机制建设欠缺等。如果能够扬长避短, 将文化 交流中心建设和澳门本土文创产业相结合，在发挥政府引领作用的同时，鼓励民间参与，澳 门一定能够真正担当中国-葡语国家文化交流的桥梁。

\section{1. 引言}

自 2003 年中国与葡语国家经贸合作论坛在澳门创立以来, 中葡论坛（澳门）历经 15 年 的发展, 已吸引 8 个葡语国家加入。通过中葡论坛 (澳门) 不断完善的机制, 中国与各葡语 国家经贸活动蓬勃展开。据中国海关总署统计, 2017 年中国与葡语国家进出口商品总值为 1175.88 亿美元, 与 2016 年相比增长 $29.4 \%$ 。在提升中国与葡语国家间经贸投资的同时, 澳 
门作为中葡论坛常设秘书处所在地, 也在促进中葡文化交流中发挥着举足轻重的作用。

历史上，澳门一直是连接东西文明的交点。不同的文化在这里相遇，互相影响，和谐共 存。虽然澳门一直是中国了解世界的前哨, 也一直发挥着文化桥梁的作用, 但正式提出把澳 门建设成 “中葡文化交流中心” 却是近几年的事。2016年，国家总理李克强在中葡论坛（澳 门）第五届部长级会议的开幕式上宣布了十八项新举措（2017-2019年），正式提出要在澳门 设立 “中国与葡语国家文化交流中心”。与此同时, 中葡论坛（澳门）第五届部长级会议经 贸合作纲领 (2017-2019) 第十三条明确表示, 文化及体育论坛对成员国经贸合作有重要作用, 并同意搭建论坛成员国间文化及体育交流的合作机制。

\section{2. 中葡文化交流活动在澳门的开展}

对于国家对澳门中葡文化交流中心的定位，澳门特区政府积极响应，举办各种活动增进 不同文化的交流，其中比较著名的有 “葡韵嘉年华”、“澳门国际幻彩大巡游”、“中国葡语国家文化周” 和 “相约澳门一中葡文化艺术节”。

历史最为悠久的是 “葡韵嘉年华”。1998年，为了庆祝六月十日 “葡侨日”，“葡韵嘉 年华” 在函仔的龙环葡韵举行。现在, “葡韵嘉年华” 吸引了十多个来自世界各地的葡语社 群参加, 参加者不仅可以品尝美味葡式料理, 还可以体验葡萄牙文化中的传统游戏和艺术表 演，可谓集吃、喝、玩、乐于一体。

“澳门国际幻彩大巡游” 虽然在2011年才首次举办, 但已成为澳门的重要文化品牌之一。 大巡游邀请不同国家和地区的表演队伍和澳门本地艺术人士一起表演, 带领澳门居民和游客 在澳门城里巡游，不仅推广了澳门独特的文化内涵，也有利于参与者了解其他文化。

“中国-葡语国家文化周” 每年举办一届，到2018年10月即将举办第十届。文化周得到 中葡论坛（澳门）常设秘书处、澳门特区政府文化局、民政总署及旅游局、东方葡萄牙语协 会、澳门巴西之家协会等多个机构和组织的倾力支持, 内容涵盖展览、歌舞、手工艺、戏剧、 美食、丝路经济带等多种方面。每届文化周还会邀请内地一个省的文化和艺术界人士参加。

2018年，澳门举办了首届 “中葡文化艺术节”，包括五大活动：中国与葡语国家电影展、 “汉文文书-东波塔档案中的澳门故事” 展览和讲座、中国与葡语国家文艺晚会、中国与葡语 国家文化论坛以及中国与葡语国家艺术年展。其中的 “中国与葡语国家文化论坛” 吸引了来 自中国内地、澳门、香港和葡萄牙、巴西、莫桑比克、安哥拉、佛得角、圣多美和普林西比、 东帝汶和几内亚比绍等8个葡语国家的政府官员和专家学者。正如谭俊荣司长在开幕式上的致 辞所言, “中国与葡语国家文化论坛” 的开设, 标志着中国与葡语国家文化艺术合作交流机 制的正式确立。

\section{3. 澳门的优势}

国家和澳门特区政府之所以要将澳门打造成 “中国与葡语国家文化交流中心”，是因为 澳门具有无可比拟的优势。

\section{1 历史、语言、文化优势}

自十六世纪葡萄牙人首次抵澳, 澳门历经明、清、民国、新中国四百多年的发展, 积累 了丰厚的资源, 已经成为华洋共处、多种文化和谐共存的城市。由于特殊的历史背景, 澳门 在语言、文化、法律体系等多方面都与葡语系国家有共通之处。澳门回归后, 葡萄牙语仍然 是特区的官方语言之一。由于和葡语国家类似的历史背景、相同的语言, 澳门参加了多个葡 语组织, 如葡语都市联盟（UCCLA），葡语系奥林匹克委员会总会（ACOLOP）等。在澳门 本地, 葡语广播、电视、报纸、杂志、葡语学校等一应俱全, 在各领域熟练掌握普通话、粤 语、葡萄牙语的人才也非鲜见。同时, 葡萄牙在澳门四百多年的存在, 造就了澳门独特的城 
市风貌。中式建筑和葡式建筑位立在碎石建成的街道两旁, 见证了中葡文化的融合。2005年, “澳门历史城区”被列入联合国《世界遗产名录》。

\section{2 地理优势}

澳门历史上是东西海上贸易航线的连接点, 现在是 “ 21 世纪海上丝绸之路” 的重要节点。 澳门毗邻广东省珠海经济特区, 连通中国大陆腹地, 与香港一衣带水, 距东南亚各国和台湾 地区都不算远。同时, 澳门的交通十分便捷, 有澳门国际机场、码头和正在建设中的轻轨, 过关到珠海便可搭乘高铁，方便与全世界各国家和地区的联系。港珠澳大桥更是把澳门、香 港和内地更加紧密的联系在一起。凭借良好的地理位置, 澳门能够积极参与区域合作中。以 CEPA (内地与澳门关于建立更紧密经贸关系的安排) 协议为例, 内地向澳门开放的重要服务 贸易领域之一就是文化领域开放。因此, 将澳门作为中葡文化交流中心，澳门便可作为中心 辐射点，将中葡文化交流中迸发的火花传播到不同地方。

\section{3 制度和政策优势}

自回归以来，在 “一国两制”方针和基本法的指导下，澳门作为特别行政区，始终享有 高度自治权。与此同时，中国人民政府始终支持把澳门建设成中国与葡语国家经贸合作服务 平台，更是把澳门“一个平台，三个中心”（中葡中小企业商贸服务中心、葡语国家食品集 散中心和中葡经贸合作会展中心）的定位写进了中葡论坛经贸合作行动纲领，国家领导人也 曾在讲话中表示澳门保持了国际都市的特色, 在中国与葡语国家的经贸关系中发挥着重要作 用。

\section{4. 澳门的局限}

\section{1 受众小}

尽管澳门拥有诸多优势，并且近些年在充当中国与葡语国家经贸往来平台方面经验更加 丰富，但同时也有不足。澳门面积小，仅 30.5 平方公里，人口少，仅 65.7 万人，其中包括约 18.1 万的外地雇员, 这就意味着各项文化活动的市场和受众较小。虽然澳门每年吸引超过 2000 万 游客, 但主要是以博彩业带动, 文化活动吸引游客的动力还不充足。目前, 澳门需要做的是 如何吸引更多人参与到文化交流活动中来，从而实现澳门-葡语文化交流向中国-葡语文化交 流的转变。

\section{2 文化交流活动有待加强制度化}

虽然澳门已成功举办多种葡语文化活动，但是没有重点项目目标，也没有一个制度化的 组织。澳门想要建设成为中葡文化交流中心，如果只是停留在每年组织几场活动层面，显然 是不够的。2018年刚刚成立的 “中国与葡语国家文化论坛” 似乎提供了常规化的组织, 但文 化论坛刚刚成立, 各项事务尚未规范化, 如何将传统的较为松散的联系进一步强化, 从而实 现中葡文化交流的常规性，需要政府、民间、学界等多方面的共同努力。

\section{5. 建议}

\section{1 文化交流中心建设与澳门文化创意产业结合}

澳门特区行政长官崔世安在2010年施政报告中提出要加大文化产业的推进力度，制定和 完善文化产业政策。2010年5月，澳门正式成立 “文化产业委员会”。五年后，澳门成立 “创 意产业协会”。把澳门打造成中葡文化交流中心也是近几年澳门特区政府的主要目标之一。 如果能将二者相结合，不仅能够合理、充分利用现有的资源，也有利于将中华文化和澳门特 
色文化向外推广。如澳门能够使文化交流中心和本土文创产业互相激励, 一定能够提升澳门 的城市软实力, 打造专属城市名片。

\section{2 政府支持和民间交往双管齐下}

除中葡论坛（澳门）常设秘书处、澳门旅游局、澳门文化局、民政总署、澳门驻里斯本 经济贸易办事处等官方机构外，澳门和各葡语国家之间还有着广泛的民间交往基础。来自世 界各地的葡语社群在澳门有对应的组织, 例如澳门安哥拉协会、中澳圣多美和普林西比友人 联谊会、澳门佛得角友好协会、几内亚比绍本土人及友好协会、果阿、达曼和第乌文化协进 会等。特区政府可通过成立发展基金等形式，对于民间开展的文化交流活动予以一定支持。

总之，澳门 “一个平台” 和 “三个中心” 的定位必然会得到进一步扩展，通过举办高层 次文化论坛和相关会议，筹办各项文化活动和展览，将中国与葡语国家文化交流常规化、机 制化, 政府牵头和民间交往互相补充, 澳门成为像爱丁堡一样凭借一个文化名片便能立于世 界的国际性都市指日可待。

\section{References}

[1] About Macao Arts Festival, Instituto Cultura, https://www.icm.gov.mo/FCP/2018/cn/ajax/AboutFCP_more, visit time: July 10th , 2018.

[2] Ding Wei and Ye Wan, "Report on Macao's Cultural Creative Industries", in Qiu Qixuan and Ding Wei, ed. Regional Development Report 2011 The Culture Creative Industries in Guangdong, Hong Kong, Taiwan and Macau (Beijing: Social Sciences Academic press (China), 2011), pp 154-189.

[3] Ip Kuai Lin, "Trend of Diversification of Cooperation among China and Portuguese-Speaking Countries and the Role of Macao as a Platform", in Wang Xian, Zhang Min and Liu Jinlan, ed. Blue Book of Portuguese-speaking Countries (2015-2016) (Beijing: Social Sciences Academic Press (China), 2017), pp 182-196.

[4] Ip Kuai Ping, Effects of the Service Platform for Economic and Trade Cooperation between China and Portuguese-speaking Countries on the Promotion of Macao's Economy with the Strategy of Appropriate Diversification, in Wang Xian, Zhang Min and Liu Jinlan, ed. Blue Book of Portuguese-speaking Countries (2015-2016) (Beijing: Social Sciences Academic Press (China), 2017), pp 167-181.

[5] Li Bingkang and Jiang Shixue, Strategy for Developing the Macao Platform (Beijing: China Social Sciences Press, 2006).

[6] Liang Anqi, Macao: the Platform between China and Portuguese-speaking Countries, Public Diplomacy Quarterly, Vol. 3, pp 69-76, 2010.

[7] New Measures of China for the 5th Ministerial Conference of the Forum for Economic and Trade Co-operation between China and Portuguese-speaking Countries (2017-2019), Permanent Secretariat of Forum for Economic and Trade Co-operation between China and Portuguese-speaking Countries (Macao), http://www.forumchinaplp.org.mo/action-plans/, visit time: July $15^{\text {th }}, 2018$.

[8] Strategic Plan for Economic and Trade Co-operation of the $5^{\text {th }}$ Ministerial Conference of the Forum for Economic and Trade Co-operation between China and Portuguese-speaking Countries (2017-2019), Permanent Secretariat of Forum for Economic and Trade Co-operation between China and Portuguese-speaking Countries (Macao), http://www.forumchinaplp.org.mo/action-plans/, visit time: July 16 ${ }^{\text {th }}, 2018$. 